\title{
Implementation of Innovative Methods for the Creation of Strategy Algorithms in CAD/CAM System Edgecam
}

\author{
Nadežda Čuboňová1*, Tomáš Dodok', Ivan Kuric', Miroslav Císar ${ }^{1}$ \\ 1 Faculty of Mechanical Engineering, Department of Automation and Production Systems, University of Žilina, \\ Univerzitna 1, 010 26, Žilina, Slovak Republic \\ * Corresponding author's e-mail: nadezda.cubonova@fstroj.uniza.sk
}

\begin{abstract}
The paper deals with the issue of the machining process optimization by using the algorithms that were proposed for the creation of NC strategies in CAD / CAM systems. The possibilities to create NC strategy in CAD / CAM systems using Feature Based Machining were analyzed using Edgecam's Strategy Manager Module, Mastercam's FBM Drill, and Machining Knowledge Editor in the Siemens NX10. Strategy Manager Module of CAD/CAM system Edgecam was suggested for experimental use. On the basis of the of NC strategy creation definition in this system, the algorithms for creating of new NC strategies were proposed, and database application for this NC strategies were created. The use of created NC strategies will eliminate the repetitive steps in creating the machining process and shorten the NC program creation.
\end{abstract}

Keywords: NC strategies, Strategy Manager, Feature Base Machining, Edgecam 2016 R2,

\section{INTRODUCTION}

Nowadays, the CAD/CAM systems are used for the preparation of NC programs for manufacturing on machine tools. They allow simulating whole manufacturing process and detecting all types of collisions. The main advantage is the ability to create NC programs for rugged parts with complex surfaces $[1,4]$.

The condition necessary to increase the efficiency of manufacturing is optimization of the manufacturing processes. Optimization of manufacturing is a complex process implemented in several stages with different methods. The machining process can be optimized with regard to the workpiece, machine tools, tools, operations, technological conditions, toolpath and so on.

Besides the possibility to optimize the production process itself, there are opportunities to optimize the sub-processes within the pre-production stages. One of those possibilities is to optimize the process NC programs creation or manufacturing process creation in CAD/CAM system, in order to eliminate the repetitive tasks performed by pro- grammers devising new manufacturing processes. Some CAD/CAM systems allow us to develop the NC strategies that can be used to optimize the creation of manufacturing sequences [10].

\section{OPTIMALIZATION IN CAD/CAM SYSTEMS}

Optimization of machining is a complex task, which is a necessary condition for high-quality solutions to technological progress in CAD/CAM systems $[2,14]$. The main tasks involve optimizing the machining process during preparation of $\mathrm{NC}$ programs or optimizing the finished $\mathrm{NC}$ programs. Optimization can be divided into two separate groups as shown in Figure 1.

The first group is focused on optimizing NC programs. This optimization is usually supported directly in the CAD/CAM systems or by external programs. CAD/CAM systems allow to optimize the NC programs according to several criteria:

- Optimization based on workpiece.

- Optimization with regard to the shape, dimensions tooling and fixtures. 
- Optimization in terms of residual material.

- Optimization using Spline interpolation.

Optimization of the machining process relates mainly to the three basic cutting conditions (in terms of optimized parameter):

- cutting speed $\left(v_{c}\right)$,

- feed rate $(f)$,

- depth of cut $\left(a_{p}\right)$.

The second group consists of optimizing the manufacturing processes, before postprocessing of NC programs. The main focus of this optimization is to reduce the time necessary to prepare manufacturing processes in $\mathrm{CAD} / \mathrm{CAM}$ system and to eliminate repetitive tasks. This type of optimization uses feature recognition and creation of $\mathrm{NC}$ strategies for manufacturing of the set of cognizable features $[12,15]$.

\section{FEATURE BASED MACHNINIG}

Feature Base Machining (i.e. FBM) allows to automate the process of NC program creation. Basically, FBM allows to recognize features on component. The features (Figure 2) are standardized shape characteristics relevant for design and manufacturing. They allow to completely and uniformly describe geometry, topology, and functional information such as tolerances, surface roughness and so on.

The principle of FBM method is in the feature recognition of the components such as holes, pockets, slots, grooves, open or closed areas, and other features. It is also possible to assign an appropriate machining process for each feature. A suitable example to demonstrate this functionality is component with two types of holes. The system recognizes these two types of holes and assigns predefined machining strategies (NC strategies) for manufacturing those holes [3].

\section{THE POSSIBILITY OF CREATION NC STRATEGIES IN CAD/CAM SYSTEMS}

Currently, there are several CAD/CAM systems that are capable of feature recognition, as well as creating NC strategies. Each mentioned

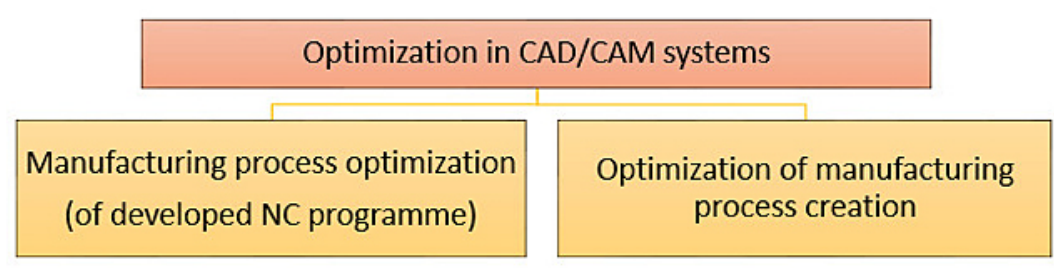

Fig. 1. Optimization in $\mathrm{CAD} / \mathrm{CAM}$ systems

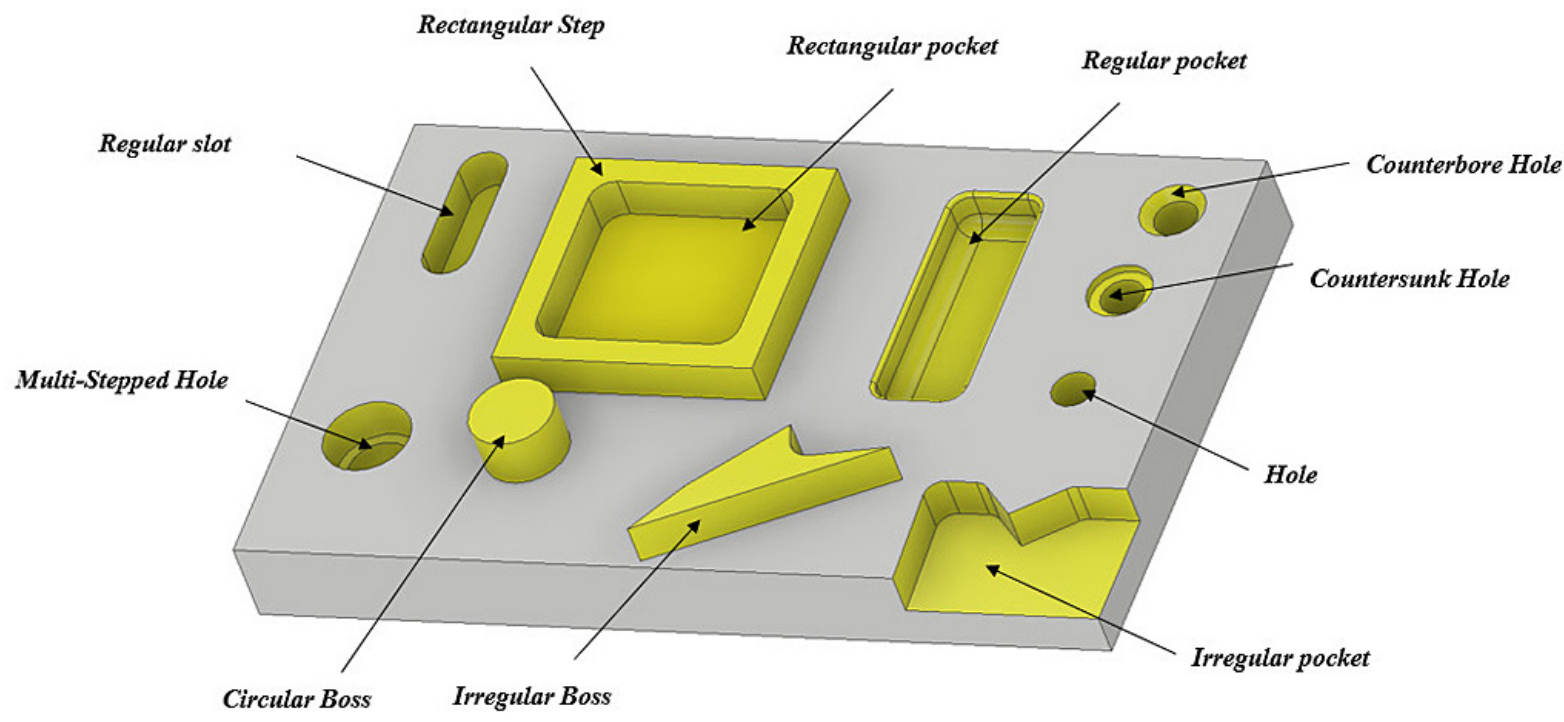

Fig. 2. Features on component 
CAD/CAM system offers different modules and therefore the approach to the creation of strategies also differs. The possibilities of creation of the NC strategies are processed in the following subsections. For the purposes of this article, the following CAD/CAM systems were compared: Edgecam 2016, Mastercam 2017, and Siemens NX 10 PLM system.

\section{CAD/CAM SYSTEM EDGECAM 2016 R2}

In order to create and edit NC strategy, the Edgecam contains a module called Strategy Manager (Figure 3). Strategy Manager allows to create new and edit older NC strategies. The user interface is divided into four main parts:

- Data - allows to insert information for NC strategies. This information is necessary for the development of conditions, such as definition of tool dimensions. The data are divided into seven groups.

- Processes - determine which machining cycles are used in NC strategies, machining processes such as roughing and finishing.

- Properties - used for creation of algorithm. For example, definition of features for which will be NC strategy used.
- Flowchart - allows to create the algorithm of NC strategies. Each block of flowchart contains the conditions for the proper functioning of the algorithm.

\section{CAD/CAM SYSTEM MASTERCAM 2017}

Mastercam is one of most used CAD/CAM systems in world. Mastercam uses two modules for the creation of NC strategies: FMB Mill for milling and FBM Drill for drilling (Figure 4). The NC strategies are created by selecting the required cycles and entering parameters. It is not necessary to handle any programming language or create flowchart of NC strategy.

\section{PLM SYSTEM SIEMENS NX 10}

PLM system NX 10 features Machining Knowledge Editor (MKE) for creating and editing the NC strategy (Figure 5). Work with this module requires programming in Visual Basic or TCL language for changing the system functions. The six basic conditions have to be defined in each NC strategy:

- InputFeatures

- OutputFeatures

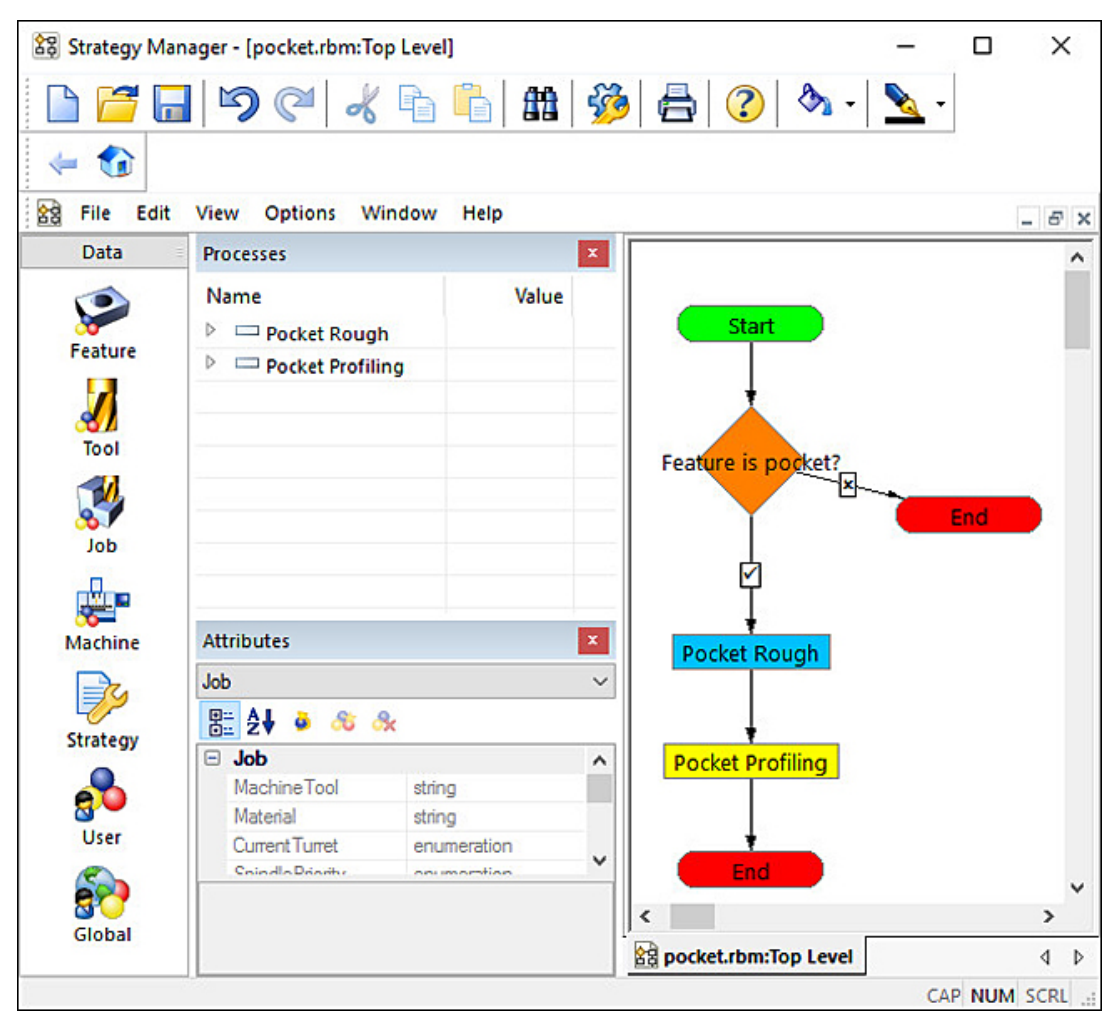

Fig. 3. Strategy Manager of CAD/CAM system Edgecam 2016 R2 


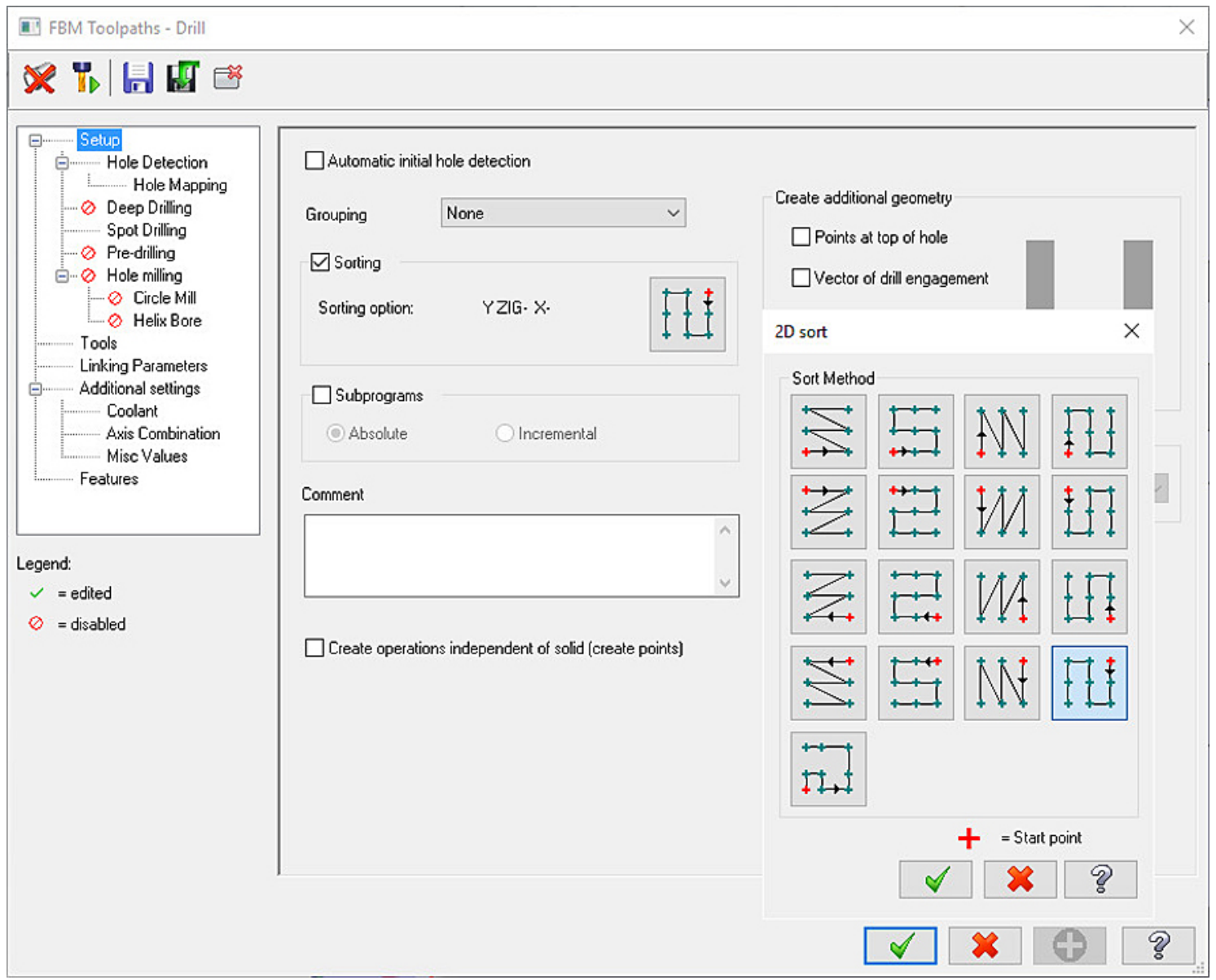

Fig. 4. FBM Drill in CAD/CAM system Mastercam 2017

: Machining Knowledge Editor - [machining_knowledge [Locked]]

I:: File Edit View Window Help

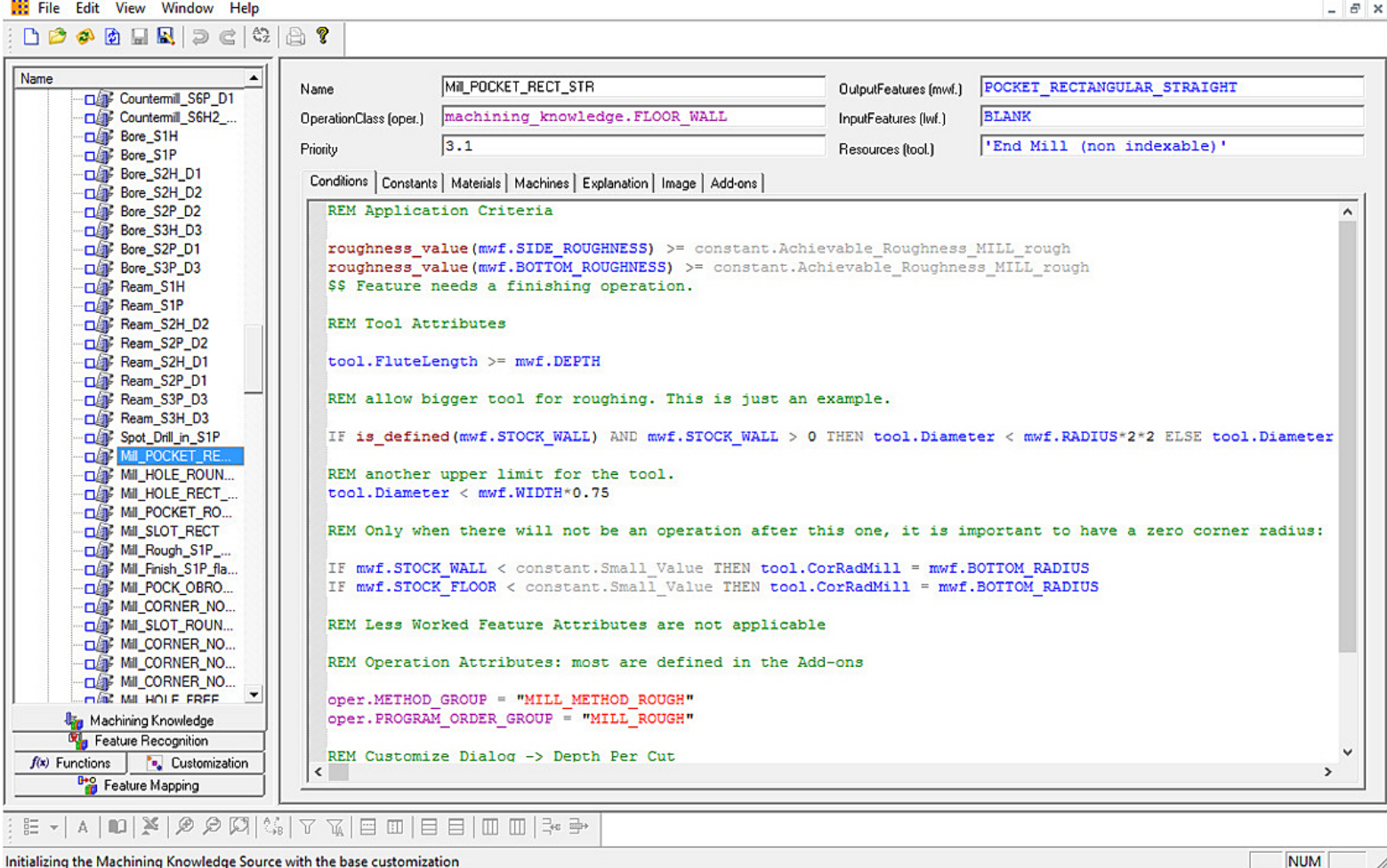

Fig. 5. Machining Knowledge Editor in PLM system Siemens NX 10 
- Name

- OperationClass

- Priority

- Resources

After determining the basic conditions, other conditions and variables must be defined. The most important part is defining rules in the Conditions tab where it is necessary to create the conditions for use of the created NC strategies. Other tabs are used for the completion and clarification of rules. Material and Machines tabs are used to define the material and machine tools. Explanation tabs is used to explain the rules and Pictures tab allows to load additional pictures. The Appendices card inserts additional parameters of conditions.

Table 1 compares all presented CAD/CAM systems based on the evaluation criteria. The criteria are focused on transparency, possibilities and transfer of information during creation of $\mathrm{NC}$ strategy. Last criteria focus on knowledge of programer and specified how the module is distributed, as part of system or a separate module.

\section{DEFINITION OF NC STRATEGIES}

The NC strategy is defined as algorithm with the conditions that define the features on which the NC strategy will be used. The NC strategy contains also machining cycles. Those machining cycles can be used for roughing and finishing operations, drilling holes, thread making and so on. The NC strategy also contains conditions for the choice of tool base e.g. for machining holes $[6,8,9,13]$.

The process of creating the machining process consists of several steps, as shown in Figure 6.
The programmer has to go through all these steps in order to create the NC program. Part of this process can be automated by using NC strategies. Input information for $\mathrm{NC}$ strategies can be divided into following three basic groups:

- Geometrical information - information defining the features and their properties. Information on shape is used to design of the conditions necessary for the creation of algorithm of the NC strategy. It may include information such as dimensions of pocket, corner radius, the depth of the pocket or the tolerances.

- Technological information - define machining cycles based on feature detection (drilling or milling), type of operation (e.g. roughing, finishing), information for choice of tool and conditions for selection of optimal cutting parameters.

- Additional information - commands to update the workpiece and for exchange of the tool.

NC strategies enable to:

- Increase effectiveness of creation of machining processes - The main advantages of creating strategies include speed of an NC program creation and also the versatility. Strategies can be used for number of components based on the similarity of geometric features.

- Reducing the time required to create machining processes - in terms of reducing the time required to prepare an $\mathrm{NC}$ program - Figure 7 and Figure 8.

- Preservation knowledge of the technologist - NC strategies can be created from existing parts (machining processes) or for specific types of shape similar components.

Creation of strategies is presented in the following chapter.

Table 1. Comparison of modules for creation of NC Strategies

\begin{tabular}{|l|c|c|c|}
\hline \multicolumn{1}{|c|}{ Evaluation criteria } & Edgecam 2016 R2 & Siemens NX 10 & Mastercam 2017 \\
\hline Transparency of created NC strategies in the user interface & High & Medium & Medium \\
\hline $\begin{array}{l}\text { Possibility of creation NC strategy based on the strict rules of } \\
\text { the system }\end{array}$ & High & High \\
\hline $\begin{array}{l}\text { Transfer of information between module and system during } \\
\text { creation of NC strategy }\end{array}$ & Yes & No \\
\hline $\begin{array}{l}\text { The complexity of programming in the creation of the NC } \\
\text { strategy (requires knowledge of programming language) }\end{array}$ & No & No \\
\hline $\begin{array}{l}\text { Module for creating NC strategy is system component or } \\
\text { additional module that can be buy alone }\end{array}$ & Yes & No & Yes \\
\hline
\end{tabular}




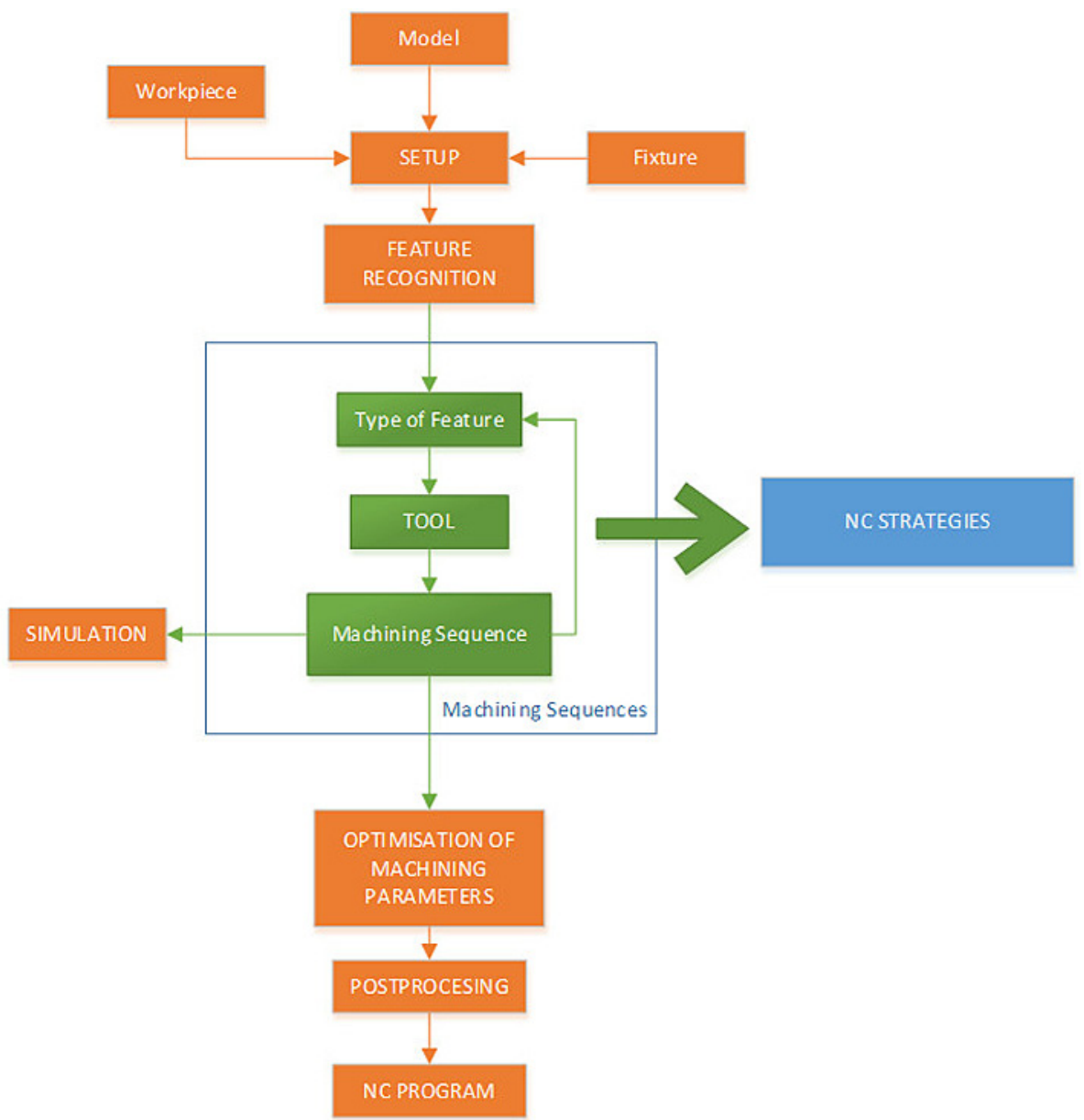

Fig. 6. The process of creating the machining process in CAD/CAM system Edgecam 2016 R2

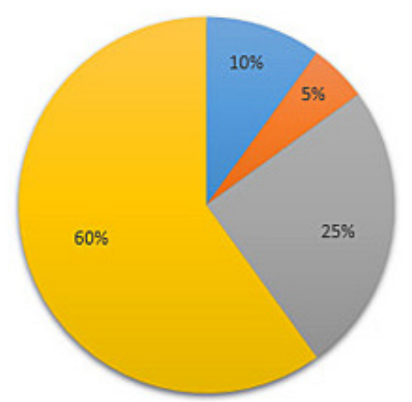

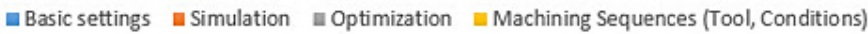

Fig. 7. Time necessary to create of an NC program without NC strategies

\section{CREATION OF EXPERIMENTAL NC STRATEGIES IN EDGECAM 2016 R2}

The process of NC Strategies creation consists of several steps in Strategy Manager [11, $7,5]$. Before the creation of an NC strategy, it is appropriate to create the machining cycle for a selected feature, for which the NC strategy is intended. Machining cycle contains the information for choosing of tool, selecting cutting conditions or additional information such as the command to update the workpiece and command for change of tool. NC strategies can also be based on the finished machining processes. The process of an NC strategy creation consists of the following steps:

- Defining the features - it is necessary to choose the feature, for which the strategy will be used. There are several types of features, e.g. FT_2D milling, FT_Hole or FT_Pocket. 


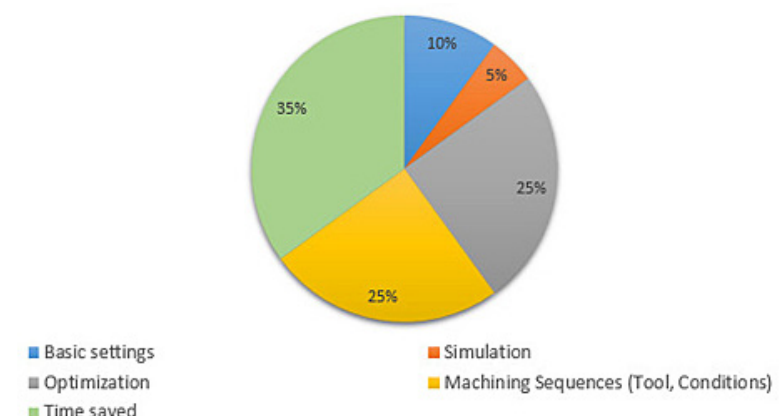

Fig. 8. Time necessary to create of an NC program with NC strategies

- Selecting of the machining process - after selecting the feature, it is necessary to create machining cycle. Machining cycle is then inserted into NC strategy including the command to "Move to Toolchange". After insertion, the Machining cycle must be adjusted so that it can be used for the same types of features with different parameters.

- Definition of the flowchart - The decision block enablesto specify the conditions and decide how the strategy works. The decision block allows user to create complex strategies and by extension to use multiple processes within a single strategy. Each block must have a specific name.

- Inserting of additional commands - command to update the workpiece and command for change of the tool.

- Connection between blocks and insertion of ends - blocks must be connected and all branches of the algorithm should be ended with end block.

Experimental NC Strategies are shown in Figure 9. Figure 9 A shows an example of the $\mathrm{NC}$ strategy for rough milling. Figure $9 \mathrm{~B}$ and $\mathrm{C}$ show Sub-Strategies for manual tool selection and automatic tool selection.

\section{DATABASE APPLICATIONS}

An important criterion for deciding to creation of the NC strategies is not only the time spent on its implementation but also sufficiency of components to which it can be applied. For this reason, a simple application was developed (Figure 10). The application helps with the decision concerning the usage of NC strategies. Before the use of application, a user must choose one component the part that represents production portfolio and can acts as appropriate substitute for any given part. Afterwards, they must select the features and their number in application. The application processes the data and gives recommendation to use or does not use of the NC strategies. The application allows to import and export database with the NC strategies.

\section{CONCLUSIONS}

Deployment of NC strategies allow to optimize the process $\mathrm{NC}$ programs creation and remove repetitive tasks. On the basis of the results achieved by solving this task, the following conclusions can be formulated:

- Regarding the possibility of creating NC strategies in CAD/CAM system Edgecam it is possible to see two main benefits. The first one is the possibility of storing knowledge and experience of a technologist. The second one is reducing the time necessary to create the $\mathrm{NC}$ program.

- Application of the experimental NC strategies allows to reduce the time of preparing machining processes in $\mathrm{CAD} / \mathrm{CAM}$ system Edgecam 2016. Reduction of time depends on the complexity of manufactured component. Total time can be reduced about a $35 \%$ by implementation of experimental NC strategies, based on the comparison of Figure 7 and 8 . That means the time necessary for the creation of machining sequences can be reduced by more that a $50 \%$.

- Second advantage of creating the strategies beside the speed of an NC program creation is also the versatility. Strategies can be used for a number of the components based on the similarity of geometric features. Comprehensive strategies for specific components can also be created. 


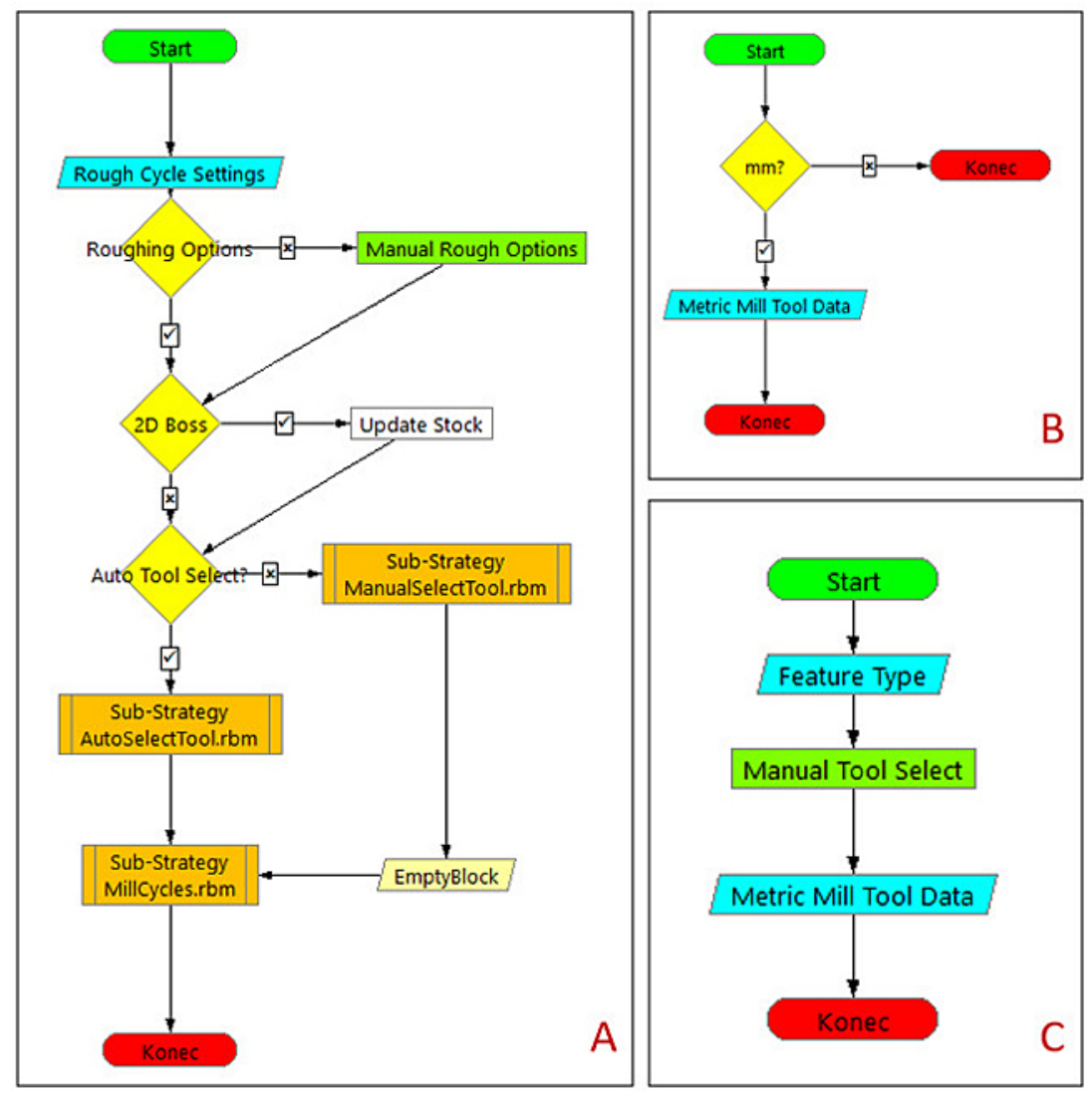

Fig. 9. A - Example of NC Strategy A - RoughMill Strategy,

B - Substrategy for AutoSelectTool, C - Substrategy for ManualSelectTool

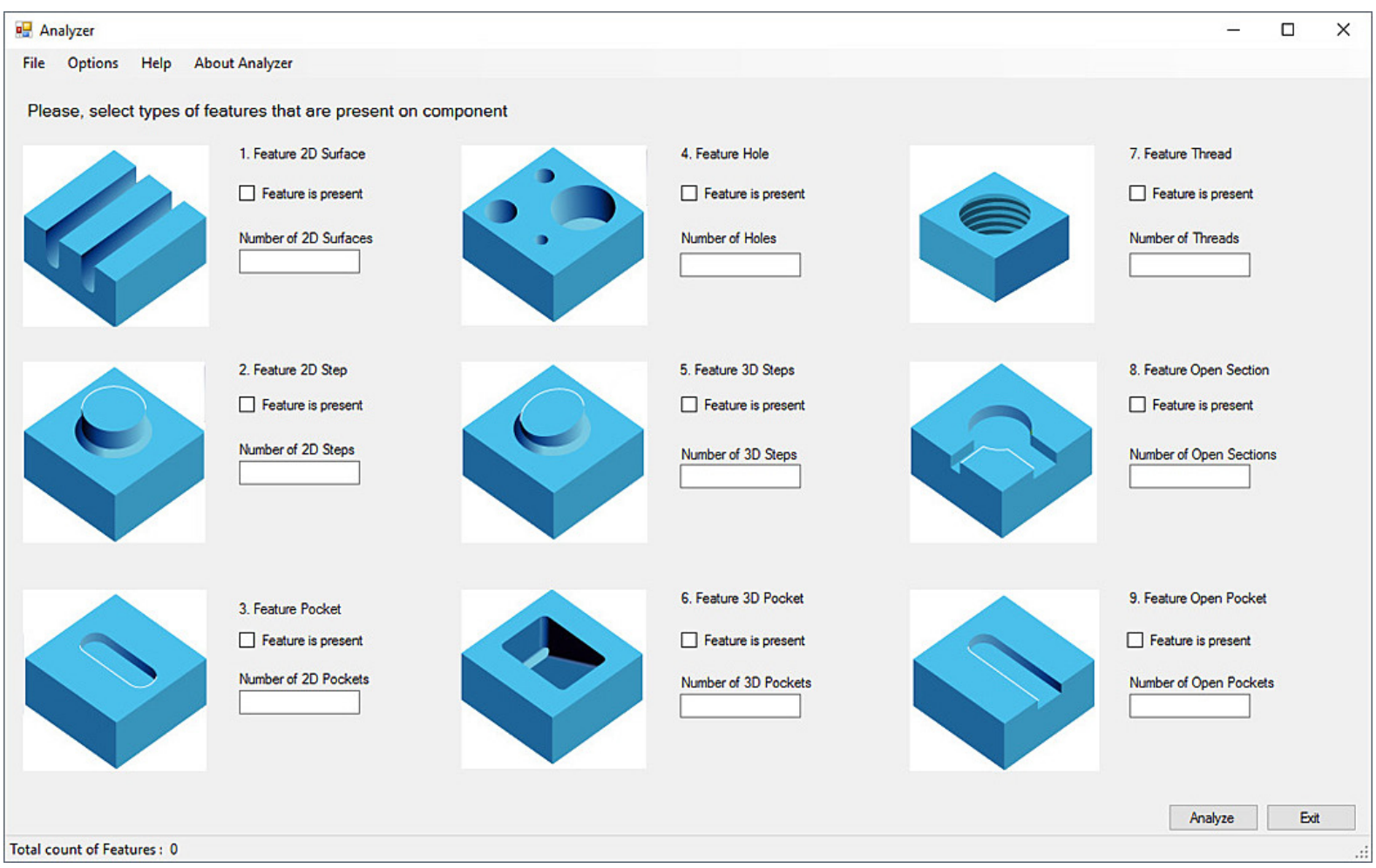

Fig. 10. Database applications for the analysis of components 
- The created database was based on the design algorithms for the creation of NC strategies. This database can be used for two purposes. The first purpose is storage of NC strategies. The second purpose is to determine the suitability of the NC strategies application for specific components.

\section{Acknowledgement}

This article was made under the support of KEGA projects - 024ŽU - 4/2016 Improving of education level and its international for students from technical study programmes based on WEB Based Training and 022ŽU - 4/2017 - Implementation of on-line education in the area of precise technologies with an impact on educational process to increase skills and flexibility of students of engineering fields of study.

\section{REFERENCES}

1. Čuboňová N. and Císar M. Design of camera mount and its application for monitoring machining process. Advances in Science and Technology, 9(26), 2015, 34-40.

2. Čuboňová N.: Genetic algorithms implemented for optimization of technological processes. Chosen applications of computer modelling in mechanical engineering. Pearson Education Limited, 2015.

3. Dodok T., Čuboňová N. and Rudawska A. Analysis of shapes for the development of algorithms for strategies of machining process in the CAM system. Academic Journal of Manufacturing Engineering, Editura Politehnica, 15(1), 2017, 6-10.

4. Dodok T., Čuboňová N. and Kuric I. Workshop Programming as a Part of Technological Preparation of Production. Advances in science and technology, 11(1), 2017, 111-116.

5. Krajcovic M., Bulej V., Sapietova A. and Kuric I. Intelligent manufacturing systems in cxoncept of digital factory. Komunikacie, 15(2), 2013, 77-87.
6. Kumičáková D., Gorski F., Milecki A. and Grajewski, D. Utilization of advanced simulation methods for solving of assembly processes automation partial tasks. Manufacturing Technology, 13(4), 2013, $478-486$.

7. Kuric I., Zajačko I. and Císar M. Analytical intelligence tools for multicriterial diagnostics of CNC machines. Advances in Science and Technology, 10(32), 2016, 59-64.

8. Kuric I. Dynamic classification system. Chosen applications of computer modelling in mechanical engineering. Pearson Education Limited, 2015.

9. Legutko S. Materials for Cutting Tools. Development of Mechanical Engineering as a Tool for the Enterprise Logistics progress, Poznan, Poland 2006, 33-49

10. Náprstková N. Students connecting to production problems resolutions in $\mathrm{CAD} / \mathrm{CAM}$ area. 9th International Scientific Konference - Engineering for rural development 2010, Jelgava, Litvia 2010, 310-314.

11. Rudawska A., Čuboňová N., Pomaranska K., Stančeková D. and Gola A. Technical and Organizational Improvements of Packaging Production Process. Advances Science and Technology, 10(30), 2016, 182-192.

12. Rudawska A., Reszka M., Warda T., Miturska I., Szabelski J., Stančeková D. and Skoczylas A. Milling as a method of surface treatment in adhesive bonding. Journal of Adhesion Science and Technology, 30(23), 2016, 2619-2636.

13. Sadílek M., Kratochvíl J., Petrů J., Cep R., Zlámal T. and Stančeková, D. Cutting tool wear monitoring with the use of impedance layers. Tehnicki Vjesnik, 21(3), 2014, 639-644.

14. Sága M., Vaško M., Čuboňová N. and Piekarska, W. Optimisation Algorithms in Mechanical Engineering Applications. Pearson, 2016.

15. Stuchlý V., Poprocký R. and Kaczmarek M. Reliability evaluation as a means of increasing the efficiency of equipment maintenance. Advances in science and technology research journal, 10(32), 2016, 40-46. 